\title{
Fate of distal aorta after frozen elephant trunk and total arch replacement for type $A$ aortic dissection in Marfan syndrome
}

\author{
Yu Chen, MD, ${ }^{a}$ Wei-Guo Ma, MD, ${ }^{\mathrm{a}, \mathrm{b}, \mathrm{c}}$ Ai-Hua Zhi, MD, ${ }^{\mathrm{b}}$ Lingeng Lu, MD, PhD, ${ }^{\mathrm{d}}$ Jun Zheng, MD, ${ }^{\mathrm{a}, \mathrm{b}}$

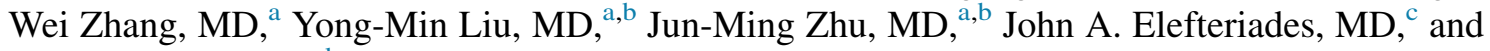 \\ Li-Zhong Sun, MD ${ }^{\mathrm{a}, \mathrm{b}}$
}

\section{ABSTRACT}

Objective: The use of the frozen elephant trunk technique for type A aortic dissection in Marfan syndrome is limited by the lack of imaging evidence for long-term aortic remodeling. We seek to evaluate the changes of the distal aorta and late outcomes after frozen elephant trunk and total arch replacement for type A aortic dissection in patients with Marfan syndrome.

Methods: Between 2003 and 2015, we performed frozen elephant trunk + total arch replacement for 172 patients with Marfan syndrome suffering from type A aortic dissection (94 acute; 78 chronic). Mean age was $34.6 \pm 9.3$ years, and 121 were male $(70.3 \%)$. Early mortality was $8.1 \%(14 / 172)$, and follow-up was complete in $98.7 \%(156 / 158)$ at a mean of $6.2 \pm 3.3$ years. Aortic dilatation was defined as a maximal diameter of greater than $50 \mathrm{~mm}$ or an average growth rate of greater than $5 \mathrm{~mm} /$ year at any segment detected by computed tomographic angiography. Temporal changes in the false and true lumens and maximal aortic size were analyzed with linear mixed modeling.

Results: After surgery, false lumen obliteration occurred in $86 \%, 39 \%, 26 \%$, and $21 \%$ at the frozen elephant trunk, unstented descending aorta, diaphragm, and renal artery, respectively. The true lumen expanded significantly over time at all segments $(P<.001)$, whereas the false lumen shrank at the frozen elephant trunk $(P<.001)$ and was stable at distal levels $(P>.05)$. Maximal aortic size was stable at the frozen elephant trunk and renal artery $(P>.05)$, but grew at the descending aorta $(P=.001)$ and diaphragm $(P<.001)$. Respective maximal aortic sizes before discharge were $40.2 \mathrm{~mm}, 32.1 \mathrm{~mm}, 31.6 \mathrm{~mm}$, and $26.9 \mathrm{~mm}$, and growth rate was $0.4 \mathrm{~mm} /$ year, $2.8 \mathrm{~mm} /$ year, $3.6 \mathrm{~mm} /$ year, and $2.6 \mathrm{~mm} /$ year. By the latest follow-up, distal maximal aortic size was stable in $63.5 \%(99 / 156)$, and complete remodeling down to the mid-descending aorta occurred in $28.8 \%$ (45/ 156). There were 22 late deaths and 23 distal reoperations. Eight-year incidence of death was $15 \%$, reoperation rate was $20 \%$, and event-free survival was $65 \%$. Preoperative distal maximal aortic size $(\mathrm{mm})$ predicted dilatation (hazard ratio, $1.11 ; P<.001$ ) and reoperation (hazard ratio, $1.07 ; P<.001$ ). A patent false lumen in the descending aorta predicted dilatation (hazard ratio, $3.88 ; P<.001$ ), reoperation (hazard ratio, 3.36; $P=.014$ ), and late death (hazard ratio, 3.31; $P=.045$ ).

Conclusions: The frozen elephant trunk technique can expand the true lumen across the aorta, decrease or stabilize the false lumen, and stabilize the distal aorta

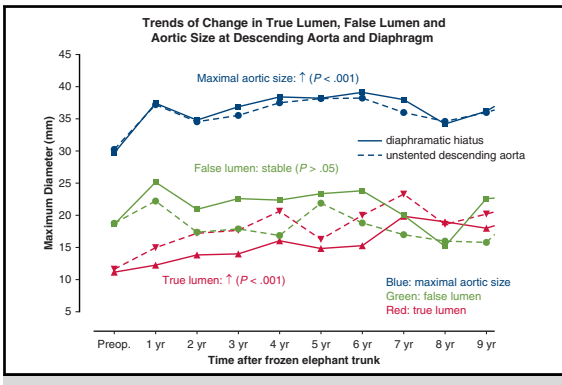

Temporal changes in the $\mathrm{TL}$ and $\mathrm{FL}$ and aortic size at the DA and diaphragm.

\section{Central Message}

In 172 patients with Marfan syndrome suffering from type A aortic dissection, the frozen elephant trunk technique induced true lumen expansion across the aorta, stabilized the distal aorta in $63.5 \%$, and achieved a $65 \%$ event-free survival at 8 years.

\section{Perspective}

The use of the frozen elephant trunk technique for type A dissection involving the aortic arch in Marfan syndrome is controversial. In this study, FET led to favorable aortic remodeling by expanding the true lumen, decreasing or stabilizing the false lumen and distal aorta, with a considerable trend toward improved survival and low reoperation rates. This study adds evidence supporting the use of FET for type A dissection in patients with Marfan syndrome.

See Commentaries on pages 850 and 852.

\footnotetext{
From the ${ }^{a}$ Department of Cardiovascular Surgery, Beijing Anzhen Hospital, Capital Medical University, and Beijing Institute of Heart Lung and Blood Vessel Diseases, Beijing, China; ${ }^{b} \mathrm{Fu}$ Wai Hospital and Cardiovascular Institute, Chinese Academy of Medical Sciences, Beijing, China; ${ }^{\mathrm{c} A o r t i c}$ Institute at Yale-New Haven, Yale School of Medicine, New Haven, Conn; and department of Chronic Disease Epidemiology, Yale School of Public Health and Center for Biomedical Data Science, Yale School of Medicine, New Haven, Conn.

This study was supported in part by the Beijing Scholar Project 2013 and Key Research Projects of Beijing Science and Technology Commission (Z171100001017083).
}

Y.C. and W.-G.M. contributed equally to this work

Read at the 98th Annual Meeting of The American Association for Thoracic Surgery, San Diego, California, April 28-May 1, 2018.

Received for publication Jan 15, 2018; revisions received June 25, 2018; accepted for publication July 11, 2018; available ahead of print Jan 8, 2019.

Address for reprints: Li-Zhong Sun, MD, Department of Cardiovascular Surgery, Beijing Anzhen Hospital, Beijing 100029, China (E-mail: lizhongsun@outlook.com). $0022-5223 / \$ 36.00$

Copyright (c) 2018 by The American Association for Thoracic Surgery

https://doi.org/10.1016/j.jtcvs.2018.07.096 


$$
\begin{array}{ll}
\text { Abbreviations and Acronyms } \\
\text { CI } & =\text { confidence interval } \\
\text { CT } & =\text { computed tomography } \\
\text { CTA } & =\text { computed tomographic angiography } \\
\text { DA } & =\text { descending aorta } \\
\text { DH } & =\text { diaphragmatic hiatus } \\
\text { DMax } & =\text { maximal aortic size } \\
\text { FET } & =\text { frozen elephant trunk } \\
\text { FL } & =\text { false lumen } \\
\text { HR } & =\text { hazard ratio } \\
\text { MFS } & =\text { Marfan syndrome } \\
\text { RA } & =\text { renal artery } \\
\text { TAAD } & =\text { type A aortic dissection } \\
\text { TAR } & =\text { total arch replacement } \\
\text { TEVAR } & =\text { thoracic endovascular aortic repair } \\
\text { TL } & =\text { true lumen }
\end{array}
$$

Scanning this QR code will take you to the article title page. To view the AATS Annual Meeting Webcast, see the URL next to the webcast thumbnail.

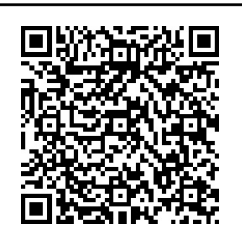

in patients with Marfan syndrome with type A aortic dissection, thereby inducing favorable remodeling in the distal aorta. This study adds long-term clinical and radiologic evidence supporting the use of the frozen elephant trunk technique for type A dissection in Marfan syndrome. (J Thorac Cardiovasc Surg 2019;157:835-49)

Aortic dissection and rupture are the main causes of death in patients with Marfan syndrome (MFS) because type A aortic dissection (TAAD) will develop in approximately $20 \%$ to $30 \%$ of patients in their lifetime. ${ }^{1}$ To date, surgical management of TAAD in MFS remains an unresolved dilemma. Although conventional proximal aortic repair has achieved favorable outcomes, ${ }^{2}$ the long-term effects are suboptimal because the unresected residual dissection, the patent false lumen (FL), and the distal aortic dilation lead to increased risks of distal aortic rupture and need for reintervention as high as 12 -fold..$^{3-5}$ As a result, total arch replacement (TAR) with frozen elephant trunk (FET) has been proposed as a more aggressive repair, ${ }^{6-9}$ which promotes the obliteration of FL and reduces distal aortic complications. ${ }^{10}$
Since 2003, we have been using the TAR + FET technique (the Sun procedure ${ }^{11}$ ) to repair TAAD involving the aortic arch for patients with MFS. ${ }^{9}$ Our previous studies have proven the benefits of the FET technique with respect to long-term survival and freedom from reoperation. $^{12,13}$ However, there is a lack of imaging evidence regarding the long-term impact of the FET on the downstream aorta in MFS. In this study, we seek to assess the long-term changes in the distal aorta and outcomes and identify the risk factors for late adverse events after the FET procedure in a large series of patients with MFS.

\section{PATIENTS AND METHODS}

The Ethics Committees of Beijing Anzhen Hospital of Capital Medical University and Fu Wai Hospital of Chinese Academy of Medical Sciences approved this retrospective study.

\section{Patients}

Between September 2003 and August 2015, 172 MFS patients (121 male, $70.3 \%$ ) with TAAD (94 acute, $54.7 \%$; 78 chronic, $45.3 \%$ ) involving the aortic arch underwent TAR and FET at our institution. Mean age was $34.6 \pm 9.3$ years (range, 17-65). The diagnosis of MFS was based on the Ghent or revised Ghent criteria. ${ }^{14,15}$

Twenty-nine patients $(16.9 \%)$ had a history of proximal aortic surgery, including the Bentall procedure in 26, ascending aortic replacement in 2, and David reimplantation in 1. Patients with a history of open or endovascular repair of the descending aorta (DA) were excluded from this study.

The extent of aortic dissection was to the iliac artery in 117 patients $(68.0 \%)$, the abdominal aorta in 21 patients $(12.2 \%)$, and the distal thoracic aorta in 34 patients $(19.8 \%)$. The entry tear was located in the ascending aorta in 135 patients $(78.5 \%)$; of those, 66 had intimal tears in the arch and 44 had a tear in the proximal DA. An arch entry tear was found in 28 patients $(16.3 \%), 11$ of whom had a tear in the DA. Nine patients $(5.2 \%)$ had an entry tear in the proximal DA. Arch vessels were involved in 165 patients $(95.9 \%)$, including the left carotid artery in $126(73.3 \%)$ and innominate artery in $139(80.8 \%)$.

Before surgery, the maximal sizes of the aortic sinus, arch, proximal descending, and abdominal aorta were $63.4 \pm 13.4 \mathrm{~mm}$, $35.8 \pm 11.6 \mathrm{~mm}, 37.3 \pm 11.6 \mathrm{~mm}$, and $26.5 \pm 8.9 \mathrm{~mm}$, respectively. On the basis of computed tomography (CT) and clinical evidence, 18 cases of preoperative malperfusion occurred in 14 patients (15 cases in 11 acute patients), including stroke in 3 , acute myocardial infarction in 4 , acute kidney injury in 4, gastrointestinal bleeding in 2, lower limb ischemia in 3 , and cardiac tamponade in 2 . The preoperative clinical profiles are listed in Table 1.

\section{Surgical Indications and Techniques}

In MFS patients with acute or chronic TAAD, we would perform TAR + FET for the following pathologies: (1) an intimal tear located in the transverse arch or DA; (2) aneurysm of the aortic arch or proximal DA (>40 mm in diameter); (3) dissection, aneurysm, or occlusion of the brachiocephalic arteries. For TAAD that is confined to the ascending aorta, we would choose an ascending aortic replacement if the arch and DA are intact, or an ascending aortic and hemiarch replacement if the proximal arch is involved. Our surgical technique of TAR and FET (the Sun operation ${ }^{11}$ ) has been described in detail previously. ${ }^{9,12,16}$ We routinely use unilateral selective antegrade cerebral perfusion through right axillary cannulation under moderate hypothermia for brain protection. 
TABLE 1. Preoperative clinical profiles

\begin{tabular}{|c|c|c|c|c|}
\hline Variable & Total $(\mathbf{n}=\mathbf{1 7 2})$ & Acute $(n=94)$ & Chronic $(n=78)$ & $P$ value \\
\hline Age, y & $34.6 \pm 9.3$ & $34.2 \pm 9.6$ & $35.0 \pm 9.1$ & .602 \\
\hline Male gender & $121(70.3 \%)$ & $72(76.6 \%)$ & $49(62.8 \%)$ & .049 \\
\hline Hypertension & $59(34.3 \%)$ & $32(34.0 \%)$ & $27(34.6 \%)$ & .937 \\
\hline Family history of aortic dissection & $71(41.3 \%)$ & $37(39.4 \%)$ & $34(43.6 \%)$ & .575 \\
\hline History of proximal aortic surgery & $29(16.9 \%)$ & $8(8.5 \%)$ & $21(26.9 \%)$ & .001 \\
\hline Composite root replacement & $26(15.1 \%)$ & $8(8.5 \%)$ & $18(23.1 \%)$ & .008 \\
\hline Ascending aortic replacement & $2(1.2 \%)$ & 0 & $2(2.6 \%)$ & .118 \\
\hline David procedure & $1(0.6 \%)$ & 0 & $1(1.3 \%)$ & .271 \\
\hline \multicolumn{5}{|l|}{ Preoperative aortic diameter, $\mathrm{mm}$} \\
\hline Aortic sinus & $63.4 \pm 13.4$ & $59.3 \pm 11.7$ & $69.2 \pm 13.7$ & $<.001$ \\
\hline Aortic arch & $35.8 \pm 11.6$ & $33.8 \pm 10.5$ & $38.2 \pm 12.4$ & .020 \\
\hline Proximal DA & $37.3 \pm 11.6$ & $35.1 \pm 10.7$ & $40.2 \pm 12.0$ & .006 \\
\hline Mid-DA & $31.0 \pm 9.3$ & $29.3 \pm 8.3$ & $33.0 \pm 10.2$ & .017 \\
\hline Diaphragm & $30.2 \pm 9.6$ & $28.2 \pm 7.8$ & $32.8 \pm 11.1$ & .005 \\
\hline Renal arteries & $26.5 \pm 8.9$ & $24.8 \pm 7.4$ & $28.7 \pm 10.1$ & .007 \\
\hline \multicolumn{5}{|l|}{ Aortic regurgitation } \\
\hline Mild or none & $47(27.3 \%)$ & $81(86.2 \%)$ & $58(74.4 \%)$ & .050 \\
\hline Moderate & $42(24.4 \%)$ & $12(12.8 \%)$ & $27(34.6 \%)$ & .001 \\
\hline Serious & $83(48.3 \%)$ & $8(8.5 \%)$ & $13(16.7 \%)$ & .104 \\
\hline Malperfusion syndrome* & $14(8.1 \%)$ & $11(11.7 \%)$ & $3(3.8 \%)$ & .061 \\
\hline Stroke* & $3(1.7 \%)$ & $2(2.1 \%)$ & $1(1.3 \%)$ & .673 \\
\hline Acute myocardial infarction & $4(2.3 \%)$ & $3(3.2 \%)$ & $1(1.3 \%)$ & .408 \\
\hline Acute kidney injury & $4(2.3 \%)$ & $3(3.2 \%)$ & $1(1.3 \%)$ & .408 \\
\hline Gastrointestinal bleeding & $2(1.2 \%)$ & $2(2.1 \%)$ & 0 & .195 \\
\hline Lower limb ischemia & $3(1.7 \%)$ & $3(3.2 \%)$ & 0 & .111 \\
\hline Acute cardiac tamponade & $2(1.2 \%)$ & $2(2.1 \%)$ & 0 & .195 \\
\hline Arch vessel involvement & $165(95.9 \%)$ & $91(96.8 \%)$ & $74(94.9 \%)$ & .522 \\
\hline Innominate artery & $139(80.8 \%)$ & $75(79.8 \%)$ & $64(82.1 \%)$ & .707 \\
\hline Left carotid artery & $126(73.3 \%)$ & $72(76.6 \%)$ & $54(69.2 \%)$ & .277 \\
\hline Left subclavian artery & $122(70.9 \%)$ & $69(73.4 \%)$ & $53(67.9 \%)$ & .433 \\
\hline
\end{tabular}

$D A$, Descending aorta. *Refers to the number of patients who had developed clinically apparent ischemia. Malperfusion of specific organs is counted by the number of cases that actually occurred, all of which were confirmed by CT scan. Acute myocardial infarction was based on the cardiac troponin I level and electrocardiogram changes. Acute kidney injury was diagnosed by an increase in serum creatinine by greater than $50 \%$ and a decreased glomerular filtration rate of less than $60 \mathrm{~mL} / \mathrm{min} / 1.73 \mathrm{~m}{ }^{2}$ and the need for dialysis.

\section{Clinical and Imaging Follow-up}

Computed tomographic angiography (CTA) of the entire aorta was performed at 1 month (or discharge), 6 months, 1 year, and annually henceforth to assess the FL, true lumen (TL), maximal aortic size (DMax) and growth rate, and complications (eg, distal new entry, endoleak, migration). CTA measurements and analyses were performed at 4 aortic levels: the stented proximal DA (FET), unstented DA, diaphragmatic hiatus (DH), and renal arteries (RAs). The statuses of the FL were classified as completely thrombosed (obliterated) if no flow was present, partially thrombosed if both flow and thrombus were present, and patent if flow was present in the absence of thrombus.

The maximum aortic diameter $(\mathrm{mm})$ was measured from the outer contours of the aortic wall in the axial plane. TL and FL diameters were measured perpendicular to the contour of the intimal flap at the level of the largest aortic size. The segmental aortic growth rate $(\mathrm{mm} / \mathrm{y})$ was assessed in patients who had undergone 2 or more $\mathrm{CT}$ scans postoperatively with an interval of at least 6 months apart and calculated by dividing the diameter differences between the first and last CTAs by the interval in between. Aortic remodeling was defined as complete disappearance of the FL with normal aortic structure and size as detected by CTA.
Open or endovascular reintervention was indicated for patients with a distal DMax of greater than $50 \mathrm{~mm}$. Earlier reintervention would be recommended for patients with a positive family history, distal new entry, or new onset of refractory chest pain.

Clinical and radiologic follow-up was complete in $98.7 \%$ (156/158) for a mean duration of $6.2 \pm 3.3$ years (median, 5.8; range, 0.2-13.8). Followup extended beyond 5 years in $55.4 \%$, beyond 8 years in $31.2 \%$, and beyond 10 years in $19.1 \%$.

\section{Study End Points}

The primary clinical end points included late death and distal aortic reoperations. Late death referred to all-cause mortality occurring in followup, excluding operative mortality (which was defined as deaths within 30 days of surgery or before final hospital discharge, including transfers). Distal aortic reoperation included any open or endovascular reintervention on the distal aorta.

Aortic dilatation was defined as a maximal diameter of greater than $50 \mathrm{~mm}$ ( $45 \mathrm{~mm}$ in patients with a family history of aortic surgery or rupture) or an average growth rate of greater than $5 \mathrm{~mm}$ /year at any aortic segment as detected by CTA during follow-up. 
TABLE 2. Operative and late outcomes

\begin{tabular}{|c|c|c|c|c|}
\hline Variable & Total $(\mathbf{n}=172)$ & Acute $(n=94)$ & Chronic $(\mathbf{n}=78)$ & $P$ value \\
\hline \multicolumn{5}{|l|}{ Operative data } \\
\hline Cardiopulmonary bypass time, min & $191.6 \pm 42.8$ & $197.6 \pm 44.1$ & $184.4 \pm 40.2$ & .044 \\
\hline Crossclamp time, min & $107.6 \pm 33.9$ & $114.3 \pm 33.9$ & $99.6 \pm 32.4$ & .004 \\
\hline Antegrade cerebral perfusion time, min & $23.7 \pm 8.0$ & $24.3 \pm 8.6$ & $22.9 \pm 7.2$ & .270 \\
\hline \multicolumn{5}{|l|}{ Concomitant procedures } \\
\hline Composite root replacement & $123(71.5 \%)$ & $71(75.5 \%)$ & $52(66.7 \%)$ & .200 \\
\hline Ascending aortic replacement & $22(12.8 \%)$ & $15(16.0 \%)$ & $7(9.0 \%)$ & .172 \\
\hline Coronary artery bypass grafting & $7(4.1 \%)$ & $5(5.3 \%)$ & $2(2.6 \%)$ & .363 \\
\hline Mitral valve surgery & $6(3.5 \%)$ & $2(3.5 \%)$ & $4(3.5 \%)$ & .992 \\
\hline Ascending aortic-femoral bypass & $9(5.2 \%)$ & $3(3.2 \%)$ & $6(7.7 \%)$ & .187 \\
\hline Abdominal aortic replacement & $2(1.2 \%)$ & $2(2.1 \%)$ & 0 & .195 \\
\hline FET diameter $(\mathrm{mm})$ & $26.2 \pm 1.5$ & $26.0 \pm 1.5$ & $26.5 \pm 1.4$ & .025 \\
\hline FET length $(\mathrm{mm})$ & $100.3 \pm 5.5$ & $100.4 \pm 5.9$ & $100.3 \pm 5.1$ & .842 \\
\hline \multicolumn{5}{|l|}{ Operative outcomes } \\
\hline Operative mortality & $14(8.1 \%)$ & $7(7.4 \%)$ & $7(9.0 \%)$ & .715 \\
\hline Operative complications & $39(22.7 \%)$ & $22(23.4 \%)$ & $17(21.8 \%)$ & .802 \\
\hline Spinal cord injury & $2(1.2 \%)$ & $2(2.1 \%)$ & 0 & .195 \\
\hline Stroke & $5(2.9 \%)$ & $3(3.2 \%)$ & $2(2.6 \%)$ & .807 \\
\hline Low cardiac output & $7(4.1 \%)$ & $4(4.3 \%)$ & $3(3.8 \%)$ & .892 \\
\hline Lower limb ischemia & $10(5.8 \%)$ & $3(3.2 \%)$ & $7(9.0 \%)$ & .107 \\
\hline Acute renal failure & $6(3.5 \%)$ & $3(3.2 \%)$ & $3(3.8 \%)$ & .816 \\
\hline Distal aortic rupture & $2(1.2 \%)$ & $2(2.1 \%)$ & 0 & .195 \\
\hline Reexploration for bleeding & $10(5.8 \%)$ & $5(5.3 \%)$ & $5(6.4 \%)$ & .761 \\
\hline \multicolumn{5}{|l|}{ Late outcomes } \\
\hline Late death & $22(12.8 \%)$ & $11(11.7 \%)$ & $11(14.1 \%)$ & .639 \\
\hline Distal aortic rupture & $9(5.2 \%)$ & $4(4.3 \%)$ & $5(6.4 \%)$ & .528 \\
\hline Heart failure and arrhythmia & $3(1.7 \%)$ & $1(1.1 \%)$ & $2(2.6 \%)$ & .454 \\
\hline Noncardiac cause & $10(5.8 \%)$ & $6(6.4 \%)$ & $4(5.1 \%)$ & .726 \\
\hline Late complications & $8(4.7 \%)$ & $8(14.0 \%)$ & $8(4.7 \%)$ & .635 \\
\hline Proximal stent leakage & $2(1.2 \%)$ & $1(1.1 \%)$ & $1(1.3 \%)$ & .894 \\
\hline Distal end of FET entering FL & $4(2.3 \%)$ & $2(2.1 \%)$ & $2(2.6 \%)$ & .816 \\
\hline Distal aortic dilatation & $57(33.1 \%)$ & $32(30.4 \%)$ & $25(32.1 \%)$ & .782 \\
\hline Distal reintervention & $23(13.4 \%)$ & $14(14.9 \%)$ & $9(11.5 \%)$ & .520 \\
\hline TAAAR & $19(11.0 \%)$ & $12(12.8 \%)$ & $7(9.0 \%)$ & .430 \\
\hline TEVAR & $4(2.3 \%)$ & $2(2.1 \%)$ & $2(2.6 \%)$ & .850 \\
\hline
\end{tabular}

FET, Frozen elephant trunk; FL, false lumen; TAAAR, thoracoabdominal aorta replacement; TEVAR, thoracic endovascular aortic repair.

\section{Statistical Analysis}

Statistical analysis was performed using SPSS for Windows 22.0 (IBM SPSS, Armonk, NY), Stata 15.1 for Mac (StataCorp LP, College Station, Tex), and Prism 7.0d for Mac (GraphPad, La Jolla, Calif). Data are expressed as the mean \pm standard deviation or number (percentage) and were compared using the Student $t$ test or Pearson chi-square test for normal distributions, and the Mann-Whitney $U$ test for abnormal distributions, as appropriate.

Risk factors for distal aortic dilatation (binary), reoperation, and late death were identified with the Cox regression model. Variables considered in multivariate analyses included acuity (binary, acute vs chronic dissection), age, gender, hypertension, preoperative maximal diameter of the distal aorta, patent FL in the DA, growth rate, and FET diameter.

Linear mixed modeling was used to evaluate the temporal trend of the changes in the maximal sizes of the FL, TL, and distal aorta. Variables considered in the linear mixed model included time after surgery (year) as a covariate and the $\mathrm{CT}$ measurement ( $\mathrm{mm}$, as the dependent variable) of the FL, TL, and aorta at the levels of FET, unstented DA, DH, and renal arteries (size $=\beta \times$ time).
Survival and freedom from aortic dilatation and reoperation were estimated using the Kaplan-Meier method, and intergroup comparisons were made with the log-rank test. Competing risks of late death and reoperation were analyzed with the Fine and Gray proportional hazards model. All tests were 2 sided and the $\alpha$ level was set at .05 .

\section{RESULTS \\ Operative Data}

The times of cardiopulmonary bypass, crossclamp, and selective unilateral antegrade cerebral perfusion were $191.6 \pm 42.8$ minutes, $107.6 \pm 33.9$ minutes, and $23.7 \pm 8.0$ minutes, respectively. The mean cooling nasopharyngeal temperature was $21.0 \pm 2.8$ (range, 15-25; $17.4 \pm 0.8$ and $21.8 \pm 2.0$ before and after January 2009, respectively). The Bentall procedure was performed in 123 patients $(71.5 \%)$ and ascending aortic replacement in 
22 patients $(12.8 \%)$. No arch debranching was performed. All valve prostheses were mechanical. Concomitant procedures included coronary artery bypass grafting in 7 patients $(4.1 \%)$, mitral valve surgery in 6 patients $(3.5 \%)$, ascending aortic to femoral bypass in 9 patients $(5.2 \%)$, and abdominal aortic replacement in 2 patients $(1.2 \%)$, respectively (Table 2).

\section{Operative Mortality and Morbidity}

The operative mortality rate was $8.1 \%$ (14/172) (Table 2). The cause of death was multiorgan failure in 6 patients $(3.5 \%)$, low cardiac output in 4 patients $(2.3 \%)$, and stroke and distal aortic rupture in 2 patients each $(1.2 \%)$.

Complications included stroke in 5 patients $(2.9 \%)$, spinal cord injury in 2 patients $(1.2 \%)$, visceral and lower limb ischemia in 10 patients $(5.8 \%)$, acute renal failure in 6 patients $(3.5 \%)$, low cardiac output in 7 patients $(4.1 \%)$, and distal aortic rupture in 2 patients $(1.2 \%)$. Reexploration for bleeding was required in 10 patients $(5.8 \%)$.

\section{Changes and Evolution of Distal Aorta}

Thrombosis of false lumen. Before discharge, complete thrombosis (obliteration) of the FL occurred at the proximal end of the FET in $98.7 \%$ of patients (154/156) and a type I endoleak was detected in 2 patients. At the distal end of FET, unstented DA, DH, and renal arteries, the FL was obliterated in $86.1 \%, 39.8 \%, 25.9 \%$, and $20.9 \%$ of patients; partial thrombosis of FL was observed in $12.0 \%$, $22.2 \%, 14.6 \%$, and $12.0 \%$ of patients, and the FL was patent in $1.9 \%, 38.0 \%, 59.5 \%$, and $67.1 \%$ of patients, respectively.

At the latest follow-up CTA, complete aortic remodeling was observed at the FET level in 56.4\% (88/156) and down to the mid-DA in $28.8 \%(45 / 156)$ of patients. In 33 patients with TAAD confined to the mid-DA, complete aortic remodeling occurred in $100 \%$, and the distal aorta remained stable in size without recurrent dissection in $97 \%(32 / 33)$ at $5.8 \pm 2.6$ years (Figure 1).

Temporal changes in false lumen, true lumen, and aorta. In linear mixed modeling, the TL showed a significant trend of expansion over time at all 4 segments $(P<.001)$, whereas the FL shrank significantly at the FET segment $(P<.001)$ and remained stable at 3 distal levels $(P>.05)$ after surgery. The DMax was stable at the levels of FET and renal arteries $(P>.05)$, but grew significantly over time at the unstented DA $(P=.001)$ and DH $(P<.001)$ (Figure 2 and Table 3$)$.

The mean DMax at the segments of the FET, DA, DH, and RA was 37.0, 30.3, 29.7, and $25.7 \mathrm{~mm}$ before surgery, measured $40.2,32.1,31.6$, and $26.9 \mathrm{~mm}$ at 1 week postoperatively, and $38.2,37.2,37.4$, and $32.3 \mathrm{~mm}$ at 1 year, respectively.

In patients with chronic TAAD, the TL showed a significant trend of expansion over time at all 4 segments $(\beta=1.720, P<.001 ; \beta=0.796, P=.014 ; \beta=0.504$,
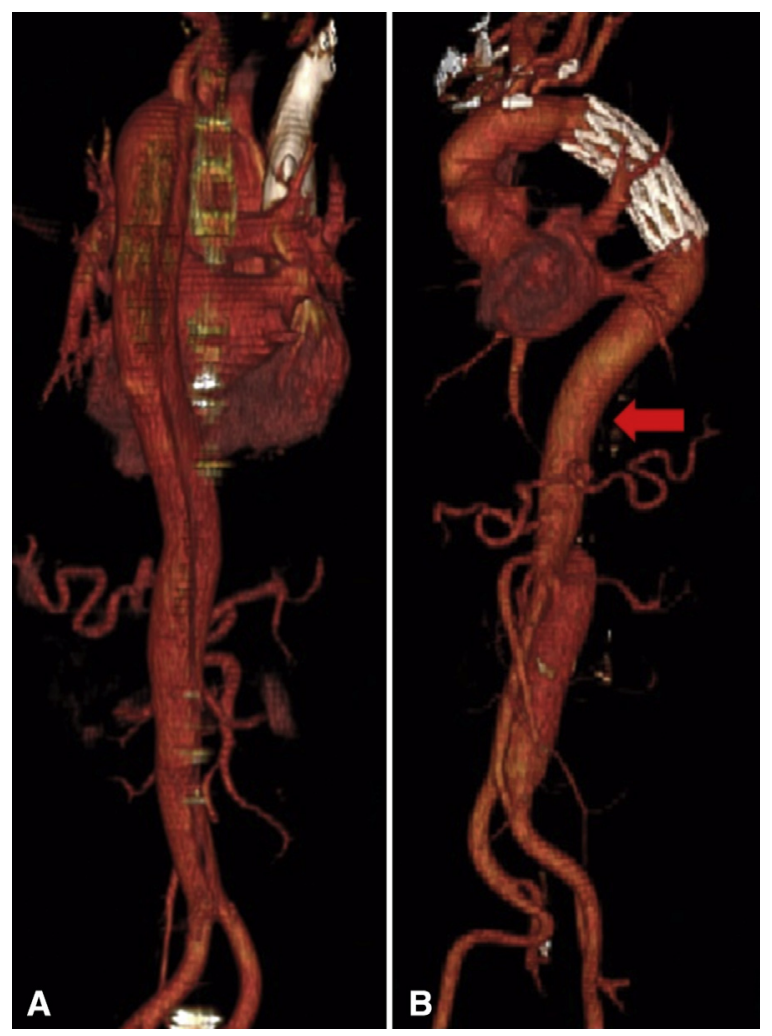

FIGURE 1. In a patient with MFS sustaining type I dissection (A), CTA at 8 years after FET showed complete aortic remodeling beyond DH (red arrow), as evidenced by disappeared FL and normal aortic structure and diameter (B).

$P=.040 ;$ and $\beta=0.658, P=.040$, respectively), whereas the FL shrank significantly at the FET segment $(\beta=-2.196, P=.031)$ and DMax was stable $(\beta=0.412, P>.05)$. The DMax and FL distal to FET remained stable at DA, DH, and RA segments $(P>.05)$. In patients with acute TAAD, the TL showed a significant trend of expansion over time at all 4 segments $(\beta=2.458$, $P<.001 ; \beta=1.674, P<.001 ; \beta=0.870, P=.001$; $\beta=0.764, P<.001$, respectively), whereas the FL shrank significantly at the FET segment $(\beta=-3.074, P<.001)$, increased at DH segment $(\beta=1.795, P=.010)$, and remained stable at DA $(\beta=-0.217, P>.05)$ and RA segments $(\beta=0.996, P>.05)$. The DMax was stable at the levels of FET $(\beta=-0.268, P>.05)$, but grew significantly over time at the unstented DA $(\beta=1.488, P<.001)$, DH $(\beta=3.037, P<.001)$, and RA $(\beta=1.865, P<.001)$.

Growth rates and distal aortic dilatation. The growth rate at the FET segment was $0.4 \mathrm{~mm} /$ year after repair. The distal aorta grew slowly over time at the DA, DH, and RA segments with a rate of $2.8,3.6$, and $2.6 \mathrm{~mm} /$ year, respectively. The DMax at DA and DH grew significantly in patients with a patent FL compared with those with partially and completely thrombosed FL (5.0 vs $1.4 \mathrm{~mm} / \mathrm{y}, P<.001 ; 5.8$ vs $2.1 \mathrm{~mm} / \mathrm{y}, P<.001)$. 


\section{Trends of Change in True Lumen, False Lumen and Aortic Size at Descending Aorta and Diaphragm}

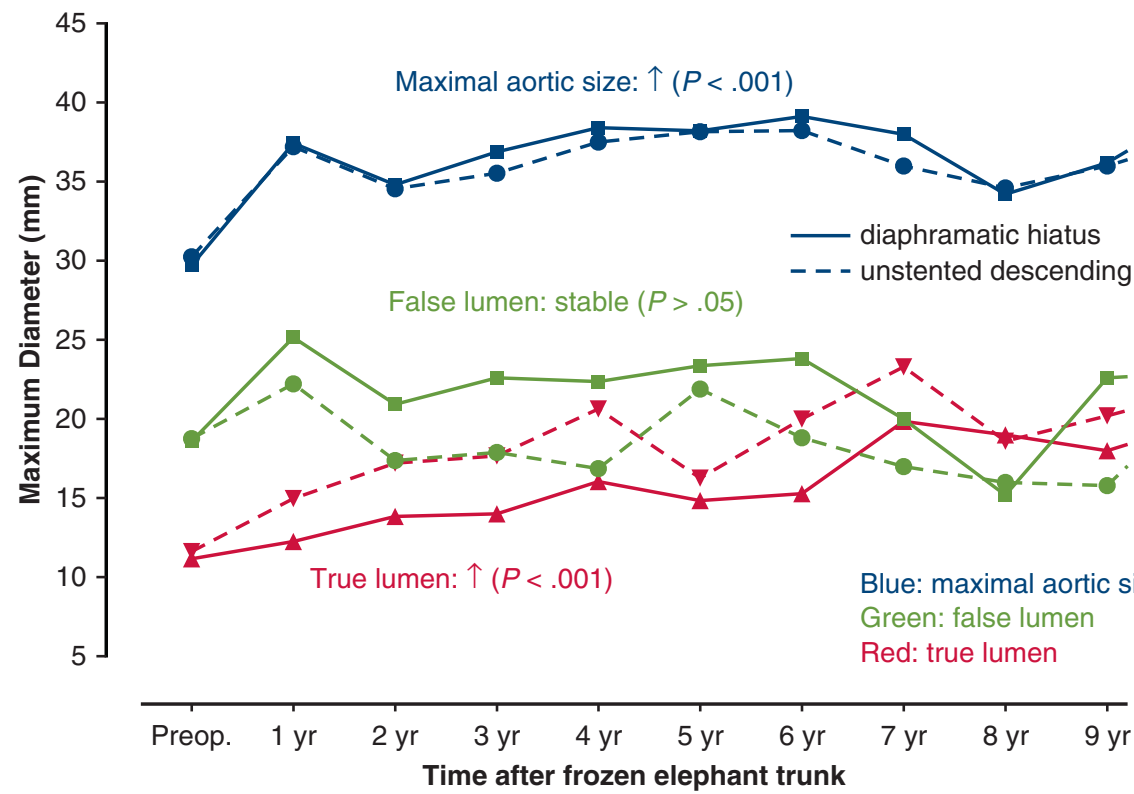

FIGURE 2. Trend of changes in the sizes of the false lumen, true lumen, and aortic segment at the levels of unstented descending aorta (dashed lines) and diaphragmatic hiatus (solid lines).

In patients with acute $\mathrm{TAAD}$, the $\mathrm{DA}$ and $\mathrm{DH}$ segments grew faster than in those with chronic TAAD (Table 4). In patients with acute TAADs, a patent FL in the DA was associated with faster aortic growth in the DA and DH (6.5 vs $1.2 \mathrm{~mm} / \mathrm{y}, P<.001 ; 7.4$ vs $2.3 \mathrm{~mm} / \mathrm{y}, P<.001$ ).

Table 5 shows the association of clinical variables with distal aortic dilation during long-term follow-up. Compared with those without dilation, patients with distal aortic dilation had significantly larger preoperative DMax, a higher percentage of patent FL, and faster growth rates $(P<.001)$. Of all patients, the maximal size of distal aorta grew significantly over time in 57 $(36.5 \% ; P<.01)$ and remained stable in $99(63.5 \%$; $P>.05$ ) (Figure 2). In the dilation group, distal dilation occurred within the first year in $42 \%(24 / 57)$ and before 5 years in $81 \%(46 / 57)$. Mean time to dilation was 3.1 (median 2.0) years after surgery. The growth rates of DMax at the DA and DH were 5.2 and $6.4 \mathrm{~mm}$ per year in the dilation group, compared with 1.9 and
$2.4 \mathrm{~mm}$ per year in the nondilation group $(P<.001)$, respectively.

Of the whole series, the freedom from distal aortic dilatation was $90.4 \%$ (95\% confidence interval [CI], 84.696.1), 69.0\% (95\% CI, 60.6-76.0), and 57.6\% (95\% CI, 46.9-66.8) at 1,5 , and 10 years, respectively. At 10 years, freedom from distal dilatation was higher in patients with completely or partially thrombosed FL (vs a patent FL) in the DA and with a preoperative DMax of less than $40 \mathrm{~mm}$ (vs $>40 \mathrm{~mm})(76.9 \%$ vs $30.2 \%, P<.001 ; 67.6 \%$ vs $34.5 \%, P<.001$ ) (Figures 3 and 4 ).

\section{Late Events and Reoperation}

Among 57 patients who developed distal aortic dilation, 22 underwent open or surgical reintervention, 12 died, and 15 were awaiting surgical repair; 8 had a distal DMax of less than $45 \mathrm{~mm}$ and were closely followed up.

Late reintervention was performed in 23 patients $(14.6 \%)$, including thoracoabdominal aortic replacement

TABLE 3. Temporal trends of changes in true lumen, false lumen, and aorta

\begin{tabular}{|c|c|c|c|c|c|c|c|c|c|}
\hline \multirow[b]{2}{*}{ Aortic segment } & \multicolumn{3}{|c|}{ True lumen } & \multicolumn{3}{|c|}{ False lumen } & \multicolumn{3}{|c|}{ DMax } \\
\hline & Trend & $\beta$ & $P$ value & Trend & $\beta$ & $P$ value & Trend & $\beta$ & $P$ value \\
\hline FET & $\uparrow$ & 2.102 & $<.001$ & $\downarrow$ & -2.959 & $<.001$ & $S$ & -0.043 & .924 \\
\hline DA & $\uparrow$ & 1.304 & $<.001$ & S & -0.072 & .890 & $\uparrow$ & 1.308 & .001 \\
\hline DH & $\uparrow$ & 0.725 & $<.001$ & S & 0.910 & .076 & $\uparrow$ & 1.698 & $<.001$ \\
\hline RA & $\uparrow$ & 0.684 & $<.001$ & $\mathrm{~S}$ & 0.706 & .104 & $\mathrm{~S}$ & 1.249 & .752 \\
\hline
\end{tabular}

In linear mixed modeling, $\uparrow$, expansion $(P<.05)$; $\downarrow$, shrinkage $(P<.05)$; S, stable $(P>.05) ; \beta$, relative effect of time. DMax, Maximal aortic size; FET, frozen elephant trunk; DA, descending aorta; $D H$, diaphragmatic hiatus; $R A$, renal artery. 
TABLE 4. Aortic growth rates $(\mathrm{mm} / \mathrm{y})$ in acute and chronic dissections $(\mathbf{n}=\mathbf{1 2 0})$

\begin{tabular}{lcccc}
\hline Aortic segment & $\begin{array}{c}\text { Whole cohort } \\
(\mathbf{n}=\mathbf{1 2 0})\end{array}$ & $\begin{array}{c}\text { Acute } \\
(\mathbf{n}=\mathbf{6 9})\end{array}$ & $\begin{array}{c}\text { Chronic } \\
(\mathbf{n}=\mathbf{5 1})\end{array}$ & $\boldsymbol{P}$ value* \\
\hline FET & 0.4 & -0.6 & 1.8 & .002 \\
Unstented DA & 2.8 & 3.5 & 2.0 & .145 \\
Diaphragm hiatus & 3.6 & 4.5 & 2.2 & .015 \\
Renal arteries & 2.6 & 3.3 & 1.7 & .031 \\
\hline
\end{tabular}

FET, Frozen elephant trunk; $D A$, descending aorta. ${ }^{*} P$ value refers to the comparison of the growth rates between the acute and chronic groups.

for distal aortic dilation in 19 and thoracic endovascular aortic repair (TEVAR) in 4. Indications for TEVAR were large residual tear in 2 and distal new entry in 1 (all with aortic dilatation). A proximal endoleak was managed with TEVAR in 1 patient.

The duration between FET and reoperation averaged $2.7 \pm 2.3$ years $(0-8$, median, 2.0$)$. Reoperation was performed within 1 year after FET in 11 patients $(48 \%)$ and before 5 years in 20 patients $(87 \%)$. Distal aortic DMax at the time of reintervention was $60.3 \pm 19.2 \mathrm{~mm}$ (range, $36-115 \mathrm{~cm}$ ). After reintervention, 23 patients were alive at a mean follow-up of $3.8 \pm 2.2$ years (range, 0.3-7.6).

Discharge CTA showed that the distal end of FET entered the FL in 4 patients. The distal aorta remained undilated in 1 patient and eventually became dilated in 3 patients, which were managed with thoracoabdominal aortic replacement. All 4 patients survived to the latest follow-up.

The freedom from reoperation on the distal aorta was 95.1\% (95\% CI, 90.7-97.8), 85.7\% (95\% CI, 78.2-90.7), and $80.1 \%(95 \% \mathrm{CI}, 70.8-86.7)$ at 1,5 , and 10 years, respectively.

At 10 years, the freedom from the distal aortic reoperation was significantly higher in patients with a completely and partially thrombosed FL (vs a patent FL) in the DA $(89.2 \%$ vs $64.6 \%, P<.001)$, and in those with a preoperative DMax of less than $40 \mathrm{~mm}(86.3 \%$ vs $63.9 \%, P<.001)$ (Figure 5).

\section{Late Survival}

Late death occurred in 22 patients (Table 2). Nine patients died of distal aortic rupture, with a distal DMax of $74.2 \pm 18.0 \mathrm{~mm}$ (range, 50-95 $\mathrm{mm}$ ) before death. Three patients died of chronic heart failure and arrhythmia, and 10 patients died of noncardiac causes.

Survival was $89.0 \%$ (95\% CI, 83.2-92.8), 85.0\% (95\% CI, 78.5-89.6), and 71.4\% (95\% CI, 61.1-79.2) at 1, 5, and 10 years, respectively, with no significant difference between patients with acute and chronic TAADs $(P=.176)$ (Figure 6).

In competing risks analysis, the incidence of late death was $15 \%$, distal reoperation was $20 \%$, and event-free survival was $65 \%$ at 8 years (Figure 7 ).
TABLE 5. Univariate analysis of potential predictive factors for late distal aortic dilation

\begin{tabular}{|c|c|c|c|}
\hline \multirow[b]{2}{*}{ Variables } & \multicolumn{2}{|c|}{ Distal aortic dilation } & \multirow[b]{2}{*}{$P$ value } \\
\hline & Yes $(\mathbf{n}=57)$ & No $(n=99)$ & \\
\hline \multicolumn{4}{|l|}{ Preoperative } \\
\hline Male gender & $48(84.2 \%)$ & $63(63.6 \%)$ & .006 \\
\hline Age $(y)$ & $32.9 \pm 9.1$ & $35.4 \pm 9.6$ & .104 \\
\hline$<35$ & $37(64.9 \%)$ & $50(50.5 \%)$ & .081 \\
\hline$\geq 35$ & $20(35.1 \%)$ & $49(49.5 \%)$ & \\
\hline Acuity of dissection & & & .753 \\
\hline Acute & $32(56.1 \%)$ & $53(53.5 \%)$ & \\
\hline Chronic & $25(43.9 \%)$ & $46(46.5 \%)$ & \\
\hline Hypertension & $23(40.4 \%)$ & $31(31.3 \%)$ & .253 \\
\hline $\begin{array}{l}\text { Family history of aortic } \\
\text { dissection }\end{array}$ & $27(47.4 \%)$ & $39(39.4 \%)$ & .332 \\
\hline $\begin{array}{l}\text { Prior proximal aortic } \\
\text { surgery }\end{array}$ & $14(24.6 \%)$ & $13(13.1 \%)$ & .069 \\
\hline \multicolumn{4}{|l|}{ Operative } \\
\hline FET diameter & $26.2 \pm 1.5$ & $26.2 \pm 1.4$ & .915 \\
\hline$<26 \mathrm{~mm}$ & $12(21.1 \%)$ & $17(17.2 \%)$ & .459 \\
\hline$\geq 26 \mathrm{~mm}$ & $45(78.9 \%)$ & $84(83.2 \%)$ & \\
\hline \multicolumn{4}{|l|}{ Imaging data* } \\
\hline Preoperative distal DMax & $44.4 \pm 13.3$ & $33.5 \pm 7.5$ & $<.001$ \\
\hline$<40 \mathrm{~mm}$ & $27(50.0 \%)$ & $70(80.5 \%)$ & $<.001$ \\
\hline $40-45 \mathrm{~mm}$ & $6(11.1 \%)$ & $8(9.2 \%)$ & \\
\hline$\geq 45 \mathrm{~mm}$ & $21(38.9 \%)$ & $9(10.3 \%)$ & \\
\hline \multicolumn{4}{|l|}{ Postoperative } \\
\hline $\begin{array}{c}\text { FL in unstented DA at } \\
\text { discharge }\end{array}$ & & & $<.001$ \\
\hline Patent & $34(63.0 \%)$ & $22(25.3 \%)$ & \\
\hline $\begin{array}{l}\text { Thrombosed (partially } \\
\text { and completely) }\end{array}$ & $20(37.0 \%)$ & $65(74.7 \%)$ & \\
\hline Aortic growth rate $(\mathrm{mm} / \mathrm{y})$ & $10.8 \pm 10.8$ & $1.9 \pm 2.2$ & $<.001$ \\
\hline$<5$ & $20(37.0 \%)$ & $78(89.7 \%)$ & $<.001$ \\
\hline$\geq 5$ & $34(63.0 \%)$ & $9(10.3 \%)$ & \\
\hline Latest distal DMax (mm) & $59.0 \pm 16.9$ & $35.2 \pm 6.7$ & $<.001$ \\
\hline$<50$ & $15(27.8 \%)$ & $83(95.4 \%)$ & $<.001$ \\
\hline$\geq 50$ & $39(72.2 \%)$ & $4(4.6 \%)$ & $<.001$ \\
\hline
\end{tabular}

DMax, Maximal aortic size; FET, frozen elephant trunk; $F L$, false lumen; $D A$, descending aorta. *Data in 141 patients had 2 or more postoperative CT scans: 54 in the dilation group and 87 in the nondilation group.

\section{Impact of Complete Aortic Remodeling}

In 88 patients $(56 \%)$ who had complete remodeling of the peri-FET aorta, survival and freedom from reoperation were marginally higher compared with those with incomplete remodeling $(P=.081$ and $P=.085)$. This marginal benefit became more pronounced when a composite outcome of death and reoperation was considered, almost reaching statistical significance $(P=.061)$ (Figure 8$)$.

\section{Risk Factors for Distal Aortic Dilation, Reoperation, and Late Death}

Table 6 shows the results of multivariate Cox regression models identifying the risk factors for distal aortic 


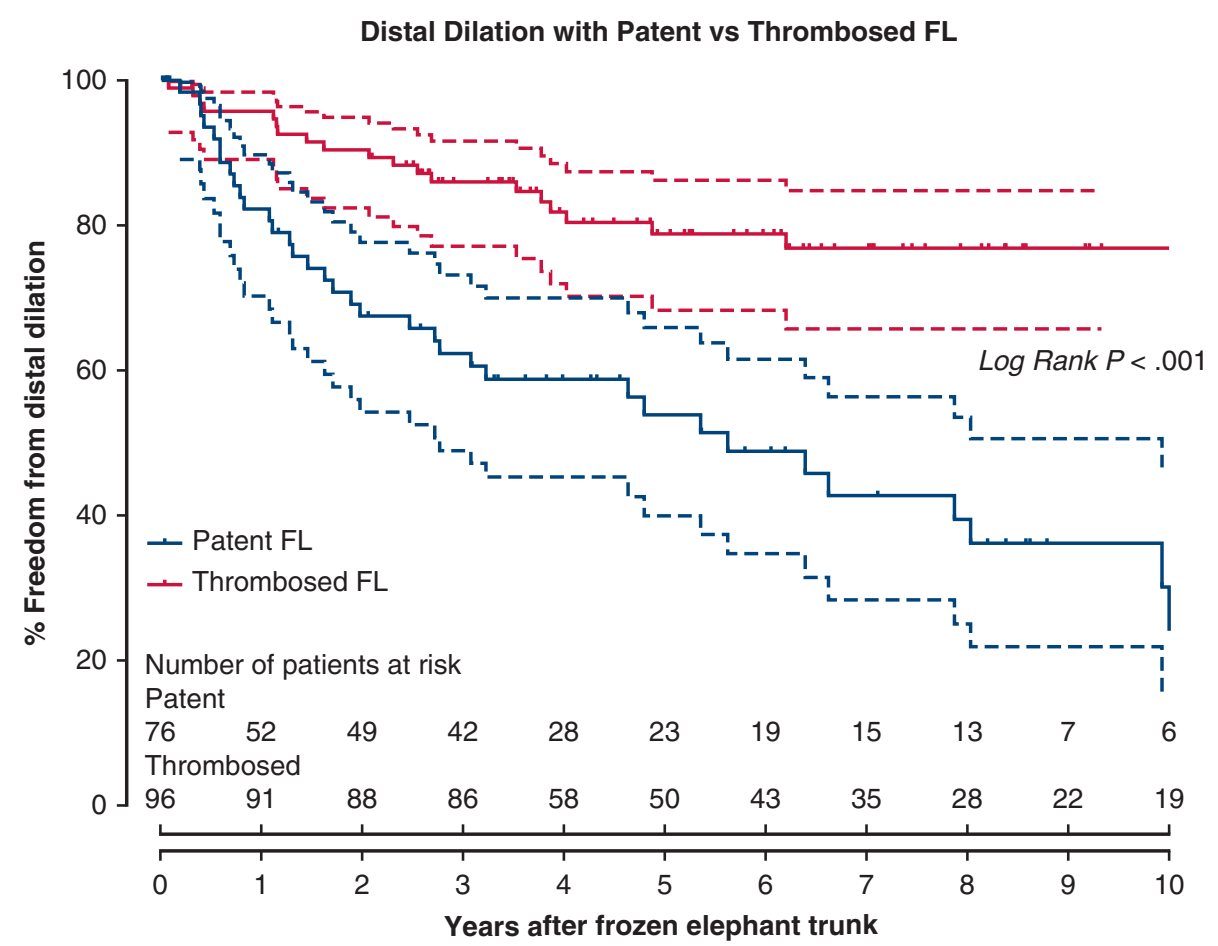

FIGURE 3. Distal aortic dilation in patent versus thrombosed FL. FL, False lumen.

dilation, reoperation, and late death, respectively. Preoperative distal DMax (mm) (hazard ratio [HR], 1.11; $95 \% \mathrm{Cl}, 1.08-1.14 ; P<.001)$, patent $\mathrm{FL}$ in the DA
(HR, 3.88; 95\% CI, 1.99-7.57; $P<.001)$, FET diameter less than $26 \mathrm{~mm}$ (HR, 3.98; 95\% Cl, 1.90-8.33; $P<.001)$, and male gender (HR, 3.35; 95\% Cl,

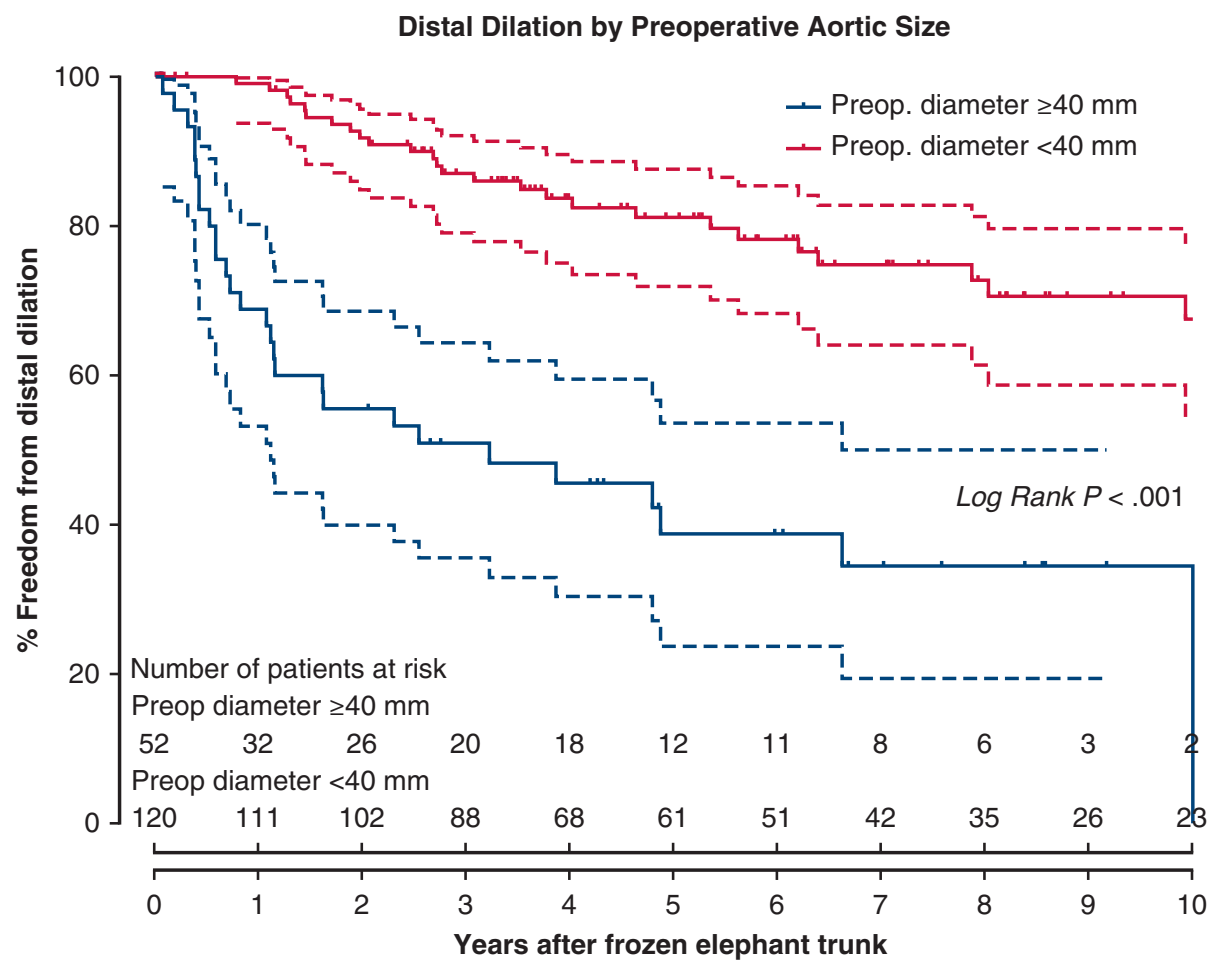

FIGURE 4. Distal dilation stratified by preoperative aortic size. 


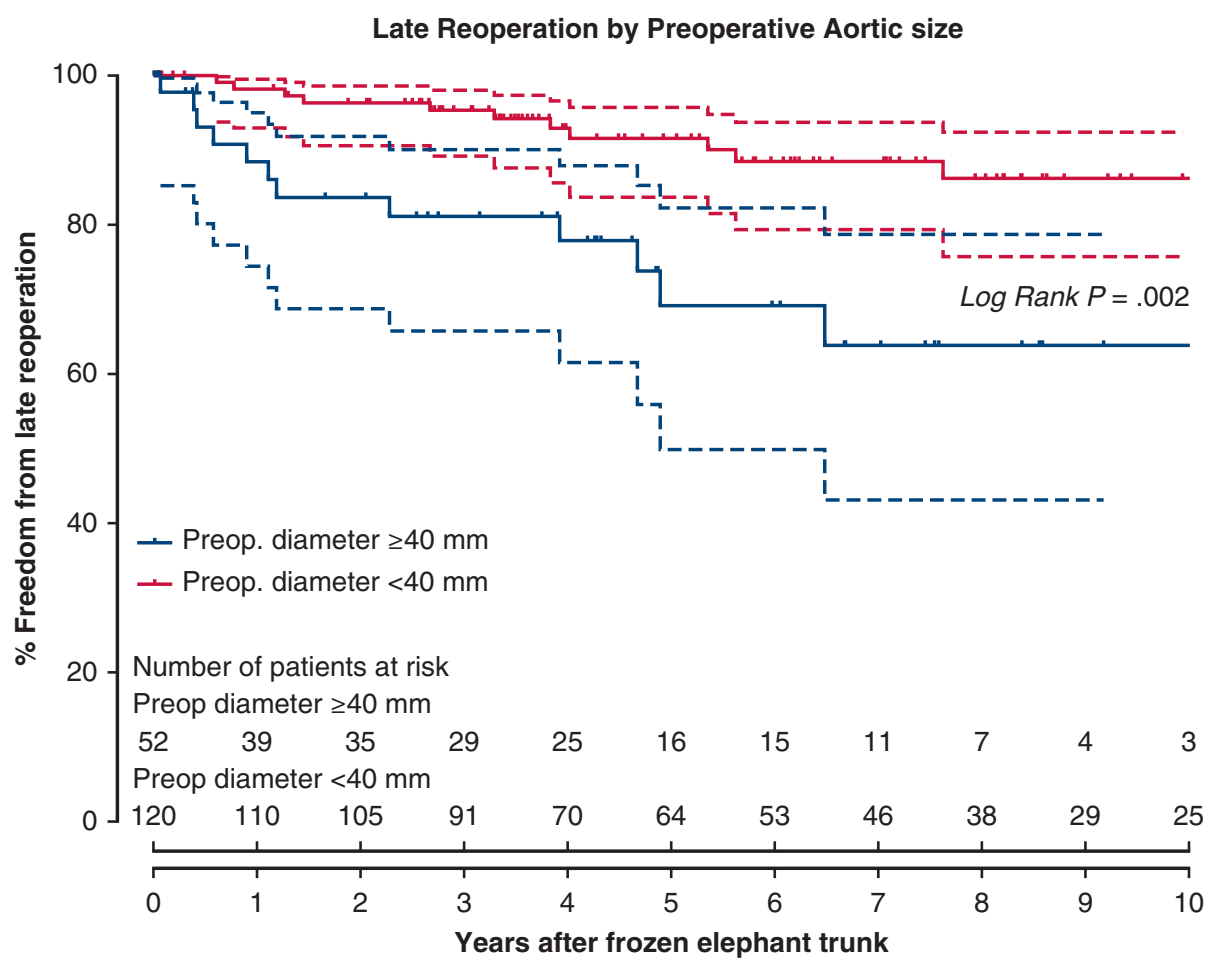

FIGURE 5. Freedom from reoperation stratified by preoperative distal aortic size.

1.52-7.37; $P=.003$ ) were predictive of distal aortic dilatation.

Risk factors for reoperation were preoperative distal DMax $(\mathrm{mm})(\mathrm{HR}, 1.07 ; 95 \% \mathrm{Cl}, 1.03-1.10 ; P<.001)$ and patent FL in the DA (HR, 3.36; $95 \% \mathrm{Cl}, 1.28-8.85$; $P=.014)$. Risk factors for late death included preoperative distal DMax $45 \mathrm{~mm}$ or greater (HR, 3.29; $95 \% \mathrm{Cl}, 1.14-$ 9.46; $P=.027)$ and patent FL in the DA (HR, 3.31; 95\% CI, $1.03-10.67 ; P=.045$ ). Acuity (acute vs chronic dissection) was not significantly associated with the risk of distal aortic dilation, reoperation, or late death, respectively (Table 6).

\section{DISCUSSION}

Total arch repair of TAAD using the FET technique is mainly limited by the concern of the high mortality and paraplegia risks after FET, ${ }^{17}$ and the lack of evidence for improved long-term outcomes and remodeling benefits on the distal aorta, ${ }^{18,19}$ and particularly the controversy on the use of stent grafts in patients with MFS and other connective tissue disorders. ${ }^{20}$ Follow-up data are scarce and inconsistent on the long-term morphologic changes in the downstream aorta after FET. ${ }^{4,21,22}$ To the best of our knowledge, no report is available regarding the temporal trends in the TL, FL, and DMax and the fate of distal aorta after FET for TAAD in large series of patients with MFS. By addressing this knowledge gap, the present study provides evidence supporting the long-term beneficial impact of the FET on the distal aorta and tackles some important issues in the management of TAAD in MFS.

The most important finding of this study is that the FET technique induced favorable remodeling of the distal aorta in this large series of MFS patients with TAAD. The extent of the initial surgery has been shown to affect the changes in the distal aorta. Park and colleagues ${ }^{21}$ reported that distal aortic expansion was caused by FL dilation after ascending aortic repair or TAR. In a recent FET series, Weiss and associates $^{4}$ found that the TL expanded in all aortic segments, the FL shrank at the FET and the thoracic aortic diameters remained stable. The present study has shown a significant temporal trend of TL expansion all across the aorta and the FL shrank significantly at the FET and stabilized in distal segments. By the latest follow-up, the size of distal aorta remained stable in $63.5 \%$ of patients, and more importantly, disappearance of FL with normal aortic segments was observed in $28.8 \%$. FL obliteration in $86 \%$ is comparable to the results reported in literature. In a single-center study of follow-up CT, Dohle and colleagues ${ }^{23}$ found that complete FL thrombosis occurred in $88 \%$ at the level of FET for acute aortic dissection. Weiss and colleagues ${ }^{4}$ reported that FL thrombosis occurred in $96 \%$ at the level of the FET in patients with aortic dissection. Nevertheless, these 2 studies included only 8 patients with MFS or connective tissue disorders. In Di Bartolomeo and colleagues' review 


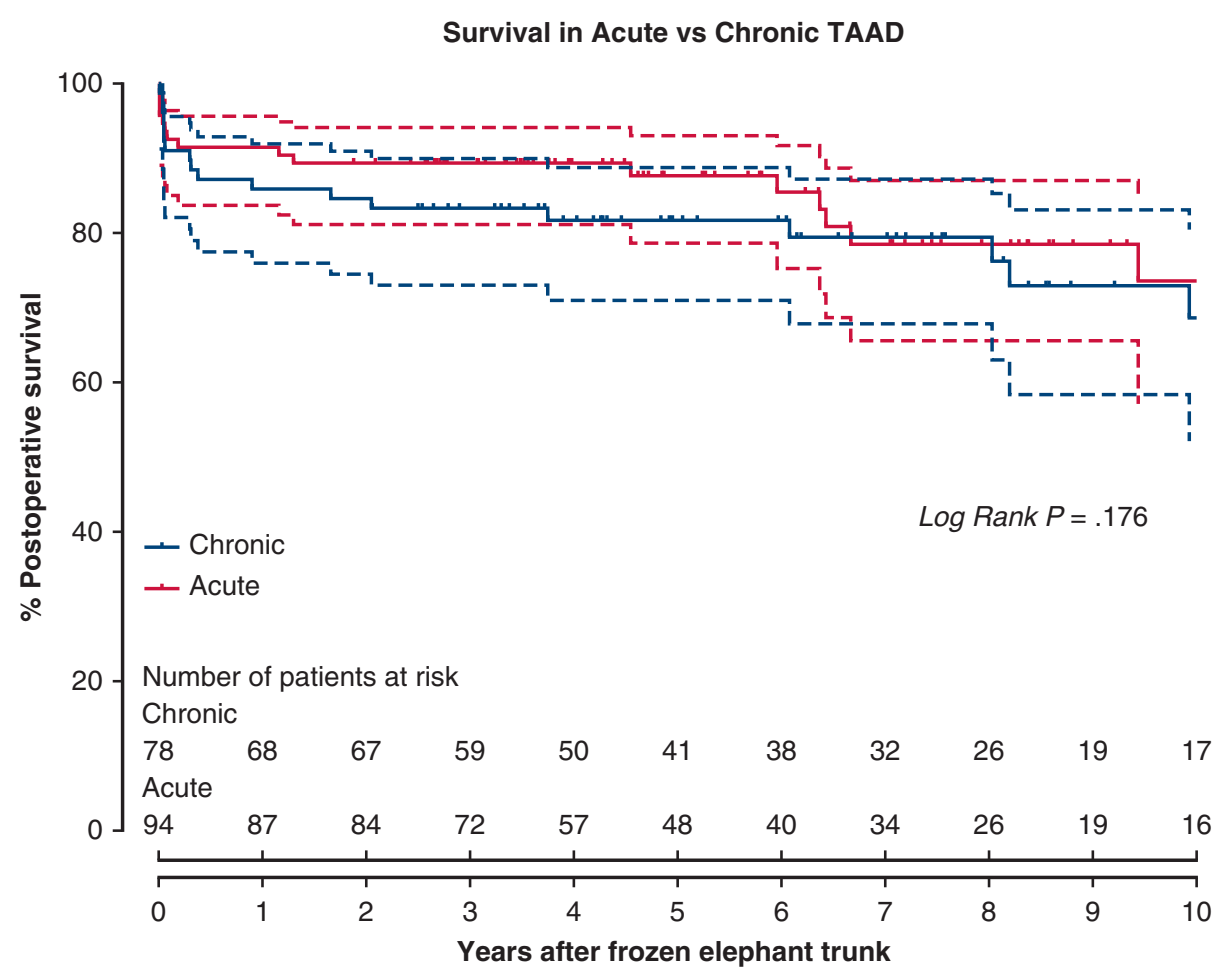

FIGURE 6. Survival in MFS with acute and chronic TAAD. TAAD, Type A aortic dissection.

of pooled data, ${ }^{24}$ partial or complete thrombosis of the periFET FL in the descending thoracic aorta was achieved in $88.9 \%$. The results of our study prove the long-term beneficial impact of the FET on the distal aorta for TAAD in
MFS, as demonstrated by the distal reoperation rate of $21 \%$ and $65 \%$ event-free survival at 10 years. This study adds radiologic evidence supporting the use of the FET technique for TAAD in patients with MFS. Given the

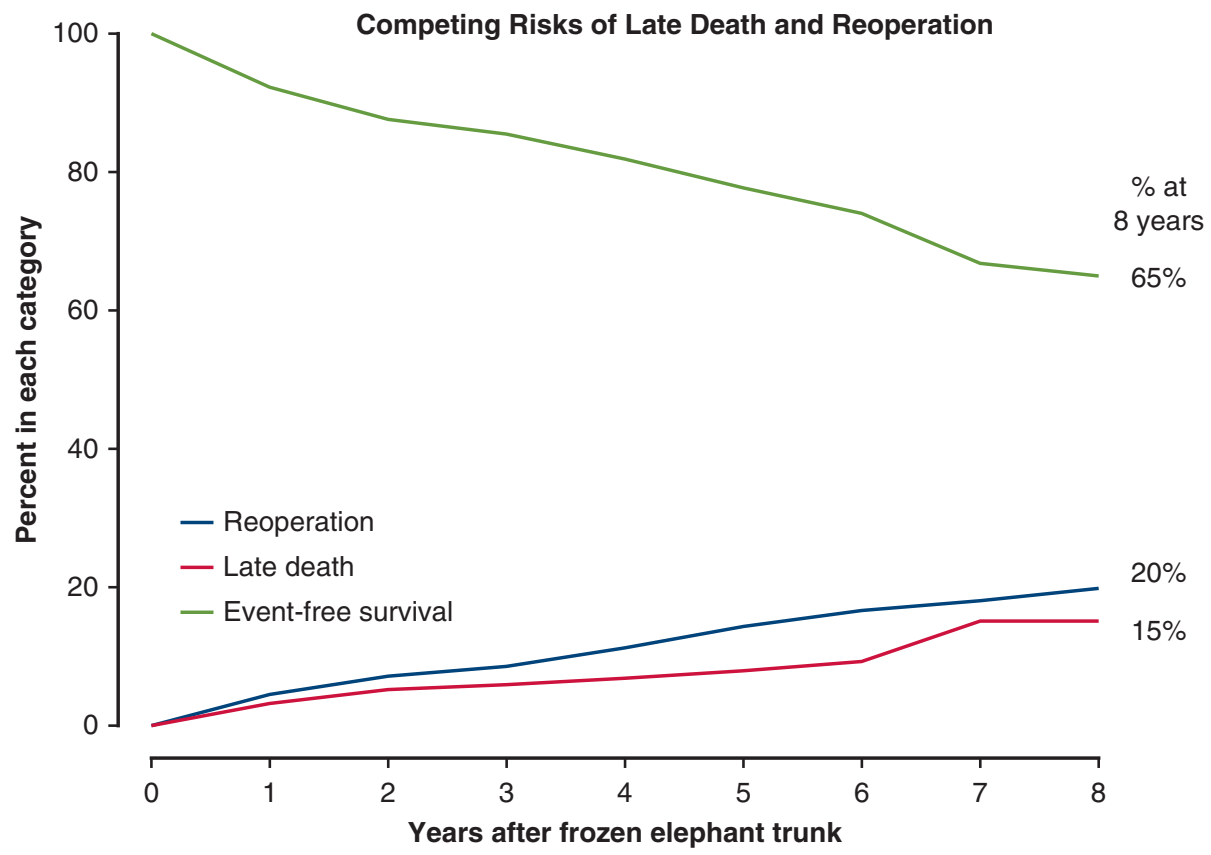

FIGURE 7. Competing risks of late death and reoperation. 


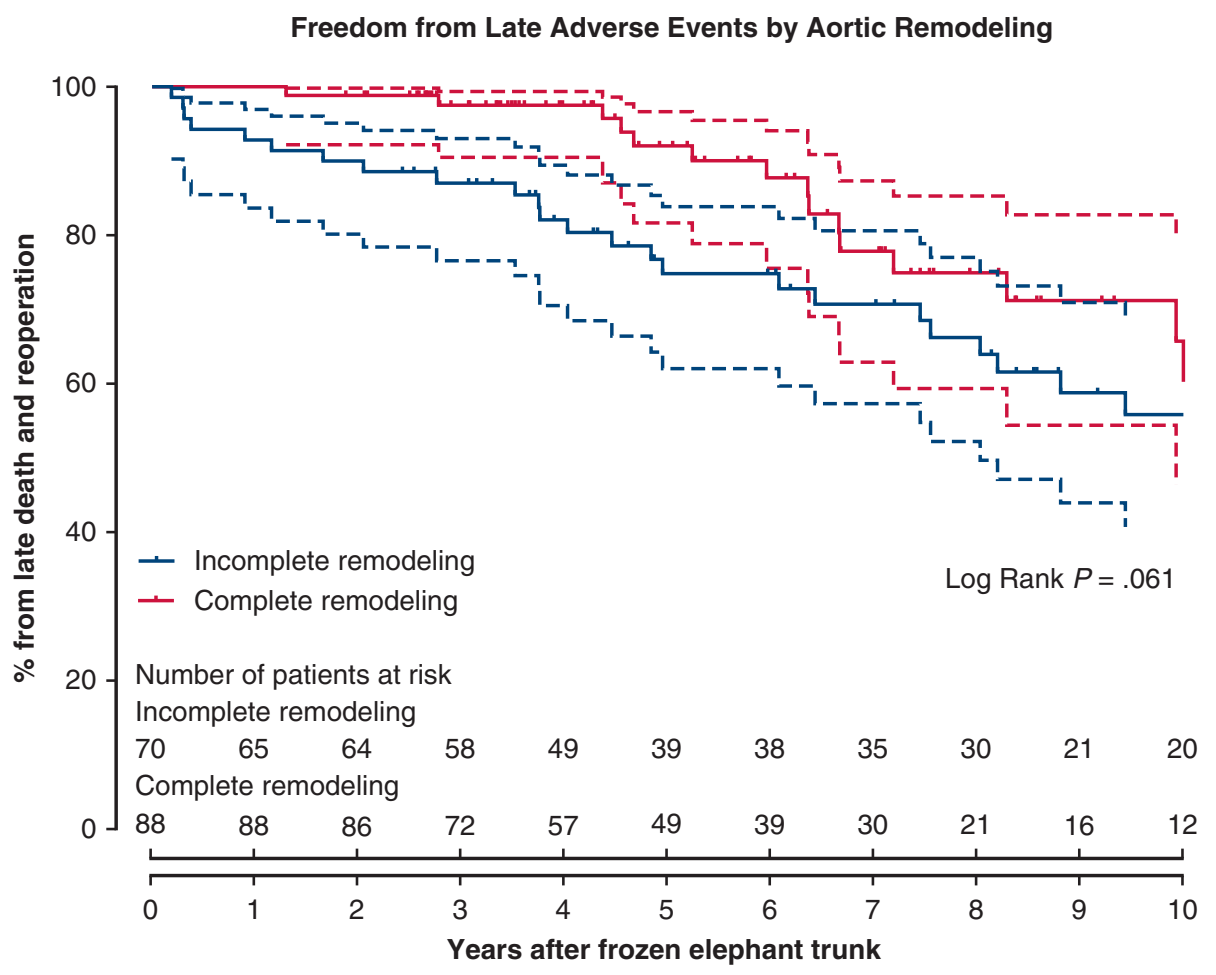

FIGURE 8. Freedom from late death and reoperation stratified by aortic remodeling.

favorable long-term clinical and radiologic outcomes, ${ }^{12}$ we propose that the FET technique be performed for all MFS patients with TAAD involving the aortic arch based on the surgeon's experience and device availability. ${ }^{25}$

This study also shows that distal aortic remodeling after FET differed between acute and chronic TAAD in MFS. The Griepp team found that the growth of distal aorta was generally slow in acute non-MFS cases. ${ }^{26}$ Dohle and colleagues $^{23}$ observed that the FET facilitated positive or stable remodeling in both acute and chronic TAADs down to the stent-graft level. In this series, both the aortic size and the FL remained stable at 4 levels in chronic TAADs, whereas the FL and DMax grew significantly at DH and were stable at the levels of unstented DA and RA in acute TAADs. Therefore, patent FL in the DH should be more closely monitored in patients with MFS who sustained acute TAAD, although FET could stabilize other aortic segments in both acute and chronic settings.

Persistent patent FL is a risk factor for late aortic dilatation and substantially affects long-term prognosis. ${ }^{21,27-31}$ Fattouch and colleagues ${ }^{3}$ found that a patent FL could predict late reoperation and death. Park and colleagues $^{21}$ observed that dilatation of the DA occurred more frequently in patients with a patent FL. The present study also identified a patent FL in DA as a risk factor for distal aortic dilatation (HR, 3.88), late reintervention (HR, 3.36), and poor survival (HR, 3.31). As an aggressive strategy, the FET procedure completely resects the entry tear in the arch and proximal DA, resulting in FL thrombus formation around the FET in $69 \%$ to $100 \%{ }^{4,8,9,21,32,33}$ In this series, complete aortic remodeling was achieved across the FET in 56\% and down to the mid-DA in $28.8 \%$, which shows the benefits of FET in promoting FL obliteration in the distal aorta for TAAD in MFS. The use of a longer FET or a bare metal stent distal to the FET to induce complete attachment (the PETTICOAT or STABILISE technique) $)^{34,35}$ may represent the technical modifications to promote FL obliteration and therefore enhance the remodeling of the entire dissected aorta.

It has been reported that distal aortic growth is faster in patients with a patent FL and in MFS. ${ }^{3,26}$ Fattori and colleagues $^{36}$ found the yearly growth rate was maximal in the DA and higher in patients with MFS with a patent FL. In this series, the aortic growth rate was minimal around the FET $(0.4 \mathrm{~mm} / \mathrm{y})$ and fastest at the $\mathrm{DH}$ $(3.6 \mathrm{~mm} / \mathrm{y})$. However, the aorta at $\mathrm{DH}$ grew slowly $(2.1 \mathrm{~mm} / \mathrm{y})$ in patients with an obliterated FL irrespective of acuity ( $2.3 \mathrm{vs} 2.2 \mathrm{~mm} / \mathrm{y})$. We speculate that the residual intimal tears distal to the FET may hinder thrombosis of the FL, which eventually led to faster growth and dilation at the DH.

Consistent with previous studies, ${ }^{3,26}$ preoperative maximal distal aortic size $(\mathrm{mm})$ was identified as a risk factor for distal aortic dilatation (HR, 1.11) and reoperation (HR, 1.07) in this series. The FET diameter $(<26 \mathrm{~mm})$ was also found to predict distal aortic 
TABLE 6. Risk factors for distal aortic dilation, late death, and reoperation in multivariate Cox regression models

\begin{tabular}{llr}
\hline \multicolumn{1}{c}{ End point/risk factor } & HR $(\mathbf{9 5} \%$ CI) & $\boldsymbol{P}$ value \\
\hline Distal aortic dilatation & & \\
Patent false lumen in DA & $3.88(1.99-7.57)$ & $<.001$ \\
Preoperative distal DMax (mm) & $1.11(1.08-1.14)$ & $<.001$ \\
FET diameter <26 mm & $3.98(1.90-8.33)$ & $<.001$ \\
Male gender & $3.35(1.52-7.37)$ & .003 \\
Acuity (acute vs chronic dissection) & $1.73(0.93-3.21)$ & .084 \\
Distal aortic reoperation & & \\
Patent false lumen in DA & $3.36(1.28-8.85)$ & .014 \\
Preoperative distal DMax (mm) & $1.07(1.03-1.10)$ & $<.001$ \\
Acuity (acute vs chronic dissection) & $2.57(0.86-7.77)$ & .094 \\
Late death & & \\
Patent false lumen in DA & $3.31(1.03-10.67)$ & .045 \\
Preoperative distal DMax $\geq 45$ mm & $3.29(1.14-9.46)$ & .027 \\
Acuity (acute vs chronic dissection) & $1.42(0.48-4.19)$ & .526 \\
\hline
\end{tabular}

$H R$, Hazard ratio; $C I$, confidence interval; $D A$, descending aorta; DMax, maximal aortic size; $F E T$, frozen elephant trunk.

dilatation. Compared with a properly sized stent graft, a smaller FET is associated with insufficient TL expansion and FL thrombosis, which may eventually lead to a patent FL and aortic dilation. Our experience shows that neither oversizing nor undersizing is advisable for patients with MFS. This implies the importance of proper sizing of the FET to optimize distal aortic modeling, which warrants further research.

Despite the association between the length of FET and the paraplegia risk, most of the stented grafts used in this series are short enough that this is not a problem, with a paraplegia rate of $1.2 \%$. However, given the findings that the distal aorta (beyond the stented portion) is at risk for growth and dilatation (ie, negative aortic remodeling), a longer FET may be considered for large intimal tears in mid-DA to promote FL thrombosis. Obviously, longer FETs should be implanted with the aid of a guidewire in the hybrid operating room. Actually, we have implanted longer $(12$ and $15 \mathrm{~cm}$ ) FETs in selected patients, and no paraplegia has occurred so far. However, close imaging surveillance is warranted to study the long-term impact on aortic remodeling in those patients.

Patients with MFS are prone to distal aortic dilation and reoperation despite extensive repair of TAAD. ${ }^{36-38}$ The 2010 American College of Cardiology/American Heart Association guidelines recommended that surgery of the distal aorta should be considered if the thoracic aortic DMax exceeded $55 \mathrm{~mm}$, thoracoabdominal DMax exceeded $60 \mathrm{~mm}$, or less with connective tissue disorders such as MFS. ${ }^{39}$ Girdauskas and colleagues ${ }^{8}$ believed that early surgical intervention was beneficial for patients with MFS when the DMax exceeded 45 to $55 \mathrm{~mm}$. Park and colleagues $^{21}$ recommended that a second operation be performed when the DMax exceeds $5.5 \mathrm{~cm}(5.0 \mathrm{~cm}$ in case of MFS). We routinely take a distal aortic DMax of greater than $50 \mathrm{~mm}$ as an absolute indication for reintervention. Of note, distal dilation occurred within the first year in $42 \%$ and before 5 years in $81 \%$; reoperations were performed within the 1 year in $48 \%$ and before 5 years in $87 \%$; and the median time to distal dilation was 2 years after FET. Therefore, it is important to balance the timing of distal reoperation with other clinical factors to prevent late rupture caused by distal dilatation. For patients with a distal DMax of $45 \mathrm{~mm}$ or less, we would recommend earlier reintervention in those with a distal new entry, a family history of rupture, or an onset of a new persistent chest pain. ${ }^{40}$ Our strategy of aggressive repair, with close imaging follow-up and antihypertensive medication, is helpful in reducing distal reoperation, detecting the progression of distal aortopathy earlier, and reintervening in a timely manner, which are essential to prevent late adverse events and improve long-term outcomes.

\section{Study Limitations}

The study is limited by the retrospective nature and lack of a control group. Most importantly, no control group of arch replacement alone was available, which precluded comparison between patients with and without FET in this series. Although the results of this study suggest that FET may prevent or delay reoperation, no definite conclusion can be drawn because of the lack of a control group without FET. Although there is limited growth in the aorta across the stent graft, it seems difficult to compare the FET with traditional elephant trunk or limited alternatives for type A dissection in MFS with our single-center results of a single procedure. Inclusion of acute and chronic type A dissections is another limitation of this study. In addition, the natural selection process should not be overlooked, which occurred while patients were transferred and while awaiting reintervention, as discussed previously. ${ }^{12}$ Follow-up CTA was not available at all time points for all survivors, which may affect the power of longitudinal analysis.

\section{CONCLUSIONS}

The FET technique can induce favorable distal aortic remodeling in patients with MFS who developed type A dissection by expanding the TL across the aorta, decreasing or stabilizing the FL, and stabilizing the distal aortic segments. Such favorable aortic remodeling leads to a considerable trend toward improved survival and low reoperation rates in the long term. This study adds long-term clinical and radiologic evidence supporting the use of FET technique for type A aortic dissection in patients with Marfan syndrome. 


\section{Webcast}

You can watch a Webcast of this AATS meeting presentation by going to: https://aats.blob.core.windows.net/media/ 18May01/28ABC\%202.Aortic\%20Endovascular/S85\%20\%20Part\%201/S85_2_webcast_021746800.mp4.

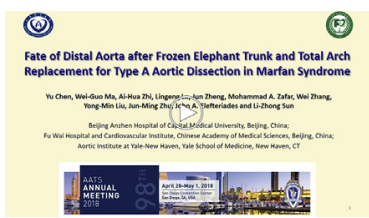

\section{Conflict of Interest Statement}

Authors have nothing to disclose with regard to commercial support.

\section{References}

1. Schoenhoff FS, Jungi S, Czerny M, Roost E, Reineke D, Matyas G, et al. Acute aortic dissection determines the fate of initially untreated aortic segments in Marfan syndrome. Circulation. 2013;127:1569-75.

2. Price J, Magruder JT, Young A, Grimm JC, Patel ND, Alejo D, et al. Long-term outcomes of aortic root operations for Marfan syndrome: a comparison of Bentall versus aortic valve-sparing procedures. J Thorac Cardiovasc Surg. 2016;151: $330-8$.

3. Fattouch K, Sampognaro R, Navarra E, Caruso M, Pisano C, Coppola G, et al. Long-term results after repair of type A acute aortic dissection according to false lumen patency. Ann Thorac Surg. 2009;88:1244-50.

4. Weiss G, Santer D, Dumfarth J, Pisarik H, Harrer ML, Folkmann S, et al. Evaluation of the downstream aorta after frozen elephant trunk repair for aortic dissections in terms of diameter and false lumen status. Eur J Cardiothorac Surg. 2016;49:118-24.

5. Rylski B, Beyersdorf F, Kari FA, Schlosser J, Blanke P, Siepe M. Acute type A aortic dissection extending beyond ascending aorta: limited or extensive distal repair. J Thorac Cardiovasc Surg. 2014;148:949-54; discussion 54.

6. Bachet J, Larrazet F, Goudot B, Dreyfus G, Folliguet T, Laborde F, et al. When should the aortic arch be replaced in Marfan patients? Ann Thorac Surg. 2007;83: S774-9; discussion S85-90.

7. Schoenhoff FS, Kadner A, Czerny M, Jungi S, Meszaros K, Schmidli J, et al. Should aortic arch replacement be performed during initial surgery for aortic root aneurysm in patients with Marfan syndrome? Eur J Cardiothorac Surg. 2013;44:346-51; discussion 51.

8. Girdauskas E, Kuntze T, Borger MA, Falk V, Mohr FW. Distal aortic reinterventions after root surgery in Marfan patients. Ann Thorac Surg. 2008;86:1815-9.

9. Sun LZ, Qi RD, Chang Q, Zhu JM, Liu YM, Yu CT, et al. Surgery for Marfan patients with acute type A dissection using a stented elephant trunk procedure. Ann Thorac Surg. 2008;86:1821-5.

10. Ma WG, Zhang W, Wang LF, Zheng J, Ziganshin BA, Charilaou P, et al. Type A aortic dissection with arch entry tear: surgical experience in 104 patients over a 12-year period. J Thorac Cardiovasc Surg. 2016;151:1581-92.

11. Ma WG, Zheng J, Zhang W, Sun K, Ziganshin BA, Wang LF, et al. Frozen elephant trunk with total arch replacement for type A aortic dissections: does acuity affect operative mortality? J Thorac Cardiovasc Surg. 2014;148:963-70; discussion 70-2.

12. Ma WG, Zhang W, Zhu JM, Ziganshin BA, Zhi AH, Zheng J, et al. Long-term outcomes of frozen elephant trunk for type A aortic dissection in patients with Marfan syndrome. J Thorac Cardiovasc Surg. 2017;154:1175-89.e2.

13. Sun LZ, Li M, Zhu JM, Liu YM, Chang Q, Zheng J, et al. Surgery for patients with Marfan syndrome with type A dissection involving the aortic arch using total arch replacement combined with stented elephant trunk implantation: the acute versus the chronic. J Thorac Cardiovasc Surg. 2011;142:e85-91.

14. De Paepe A, Devereux RB, Dietz HC, Hennekam RC, Pyeritz RE. Revised diagnostic criteria for the Marfan syndrome. Am J Med Genet. 1996;62:417-26.
15. Loeys BL, Dietz HC, Braverman AC, Callewaert BL, De Backer J, Devereux RB et al. The revised Ghent nosology for the Marfan syndrome. J Med Genet. 2010; 47:476-85.

16. Ma WG, Zhu JM, Zheng J, Liu YM, Ziganshin BA, Elefteriades JA, et al. Sun's procedure for complex aortic arch repair: total arch replacement using a tetrafurcate graf with stented elephant trunk implantation. Ann Cardiothorac Surg. 2013;2:642-8.

17. Kouchoukos NT. The frozen elephant trunk. J Thorac Cardiovasc Surg. 2015; 150:745-6.

18. Shrestha M, Bachet J, Bavaria J, Carrel TP, De Paulis R, Di Bartolomeo R, et al Current status and recommendations for use of the frozen elephant trunk technique: A position paper by the vascular domain of EACTS. Eur J Cardiothorac Surg. 2015;47:759-69.

19. Jakob H, Dohle D, Benedik J, Janosi RA, Schlosser T, Wendt D, et al. Long-term experience with the E-vita Open hybrid graft in complex thoracic aortic disease. Eur J Cardiothorac Surg. 2017;51:329-38.

20. Svensson LG, Kouchoukos NT, Miller DC, Bavaria JE, Coselli JS, Curi MA, et al. Expert consensus document on the treatment of descending thoracic aortic disease using endovascular stent-grafts. Ann Thorac Surg. 2008;85:S1-41.

21. Park KH, Lim C, Choi JH, Chung E, Choi SI, Chun EJ, et al. Midterm change of descending aortic false lumen after repair of acute type I dissection. Ann Thorac Surg. 2009;87:103-8.

22. Iafrancesco M, Goebel N, Mascaro J, Franke UFW, Pacini D, Di Bartolomeo R, et al. Aortic diameter remodelling after the frozen elephant trunk technique in aortic dissection: results from an international multicentre registry. Eur J Cardiothorac Surg. 2017;52:310-8.

23. Dohle DS, Tsagakis K, Janosi RA, Benedik J, Kuhl H, Penkova L, et al. Aortic remodelling in aortic dissection after frozen elephant trunk. Eur J Cardiothorac Surg. 2016:49:111-7.

24. Di Bartolomeo R, Pantaleo A, Berretta P, Murana G, Castrovinci S, Cefarelli M, et al. Frozen elephant trunk surgery in acute aortic dissection. $J$ Thorac Cardiovasc Surg. 2015;149:S105-9.

25. Ma WG, Zheng J, Sun LZ, Elefteriades JA. Open stented grafts for frozen elephant trunk technique: Technical aspects and current outcomes. Aorta (Stamford). 2015;3:122-35.

26. Halstead JC, Meier M, Etz C, Spielvogel D, Bodian C, Wurm M, et al. The fate of the distal aorta after repair of acute type A aortic dissection. J Thorac Cardiovasc Surg. 2007;133:127-35.

27. Murzi M, Tiwari KK, Farneti PA, Glauber M. Might type A acute dissection repair with the addition of a frozen elephant trunk improve long-term survival compared to standard repair? Interact Cardiovasc Thorac Surg. 2010;11:98-102.

28. Ergin MA, Phillips RA, Galla JD, Lansman SL, Mendelson DS, Quintana CS et al. Significance of distal false lumen after type A dissection repair. Ann Thorac Surg. 1994:57:820-4; discussion 5.

29. Sakaguchi G, Komiya T, Tamura N, Kimura C, Kobayashi T, Nakamura H, et al. Patency of distal false lumen in acute dissection: extent of resection and prognosis. Interact Cardiovasc Thorac Surg. 2007;6:204-7.

30. Evangelista A, Salas A, Ribera A, Ferreira-Gonzalez I, Cuellar H, Pineda V, et al Long-term outcome of aortic dissection with patent false lumen: predictive role of entry tear size and location. Circulation. 2012;125:3133-41.

31. Geisbuesch S, Schray D, Bischoff MS, Lin HM, Di Luozzo G, Griepp RB. Frequency of reoperations in patients with Marfan syndrome. Ann Thorac Surg. 2012;93:1496-501.

32. Uchida N, Shibamura H, Katayama A, Shimada N, Sutoh M, Ishihara H. Operative strategy for acute type A aortic dissection: ascending aortic or hemiarch versus total arch replacement with frozen elephant trunk. Ann Thorac Surg. 2009;87:773-7.

33. Pacini D, Tsagakis K, Jakob H, Mestres CA, Armaro A, Weiss G, et al. The frozen elephant trunk for the treatment of chronic dissection of the thoracic aorta: a multicenter experience. Ann Thorac Surg. 2011;92:1663-70; discussion 70.

34. Hofferberth SC, Newcomb AE, Yii MY, Yap KK, Boston RC, Nixon IK, et al. Combined proximal stent grafting plus distal bare metal stenting for managemen of aortic dissection: Superior to standard endovascular repair? J Thorac Cardiovasc Surg. 2012;144:956-62; discussion 62.

35. Faure EM, El Batti S, Abou Rjeili M, Ben Abdallah I, Julia P, Alsac JM. Stentassisted, balloon-induced intimal disruption and relamination of aortic dissection in patients with Marfan syndrome: midterm outcomes and aortic remodeling. $J$ Thorac Cardiovasc Surg. 2018;156:1787-93.

36. Fattori R, Bacchi-Reggiani L, Bertaccini P, Napoli G, Fusco F, Longo M, et al. Evolution of aortic dissection after surgical repair. Am J Cardiol. 2000;86:868-72.

37. Kalkat MS, Rahman I, Kotidis K, Davies B, Bonser RS. Presentation and outcome of Marfan's syndrome patients with dissection and thoraco-abdominal aortic aneurysm. Eur J Cardiothorac Surg. 2007:32:250-4. 
38. Schoenhoff FS, Carrel TP. Re-interventions on the thoracic and thoracoabdominal aorta in patients with Marfan syndrome. Ann Cardiothorac Surg. 2017;6: 662-71.

39. Hiratzka LF, Bakris GL, Beckman JA, Bersin RM, Carr VF, Casey DE Jr, et al. 2010 ACCF/AHA/AATS/ACR/ASA/SCA/SCAI/SIR/STS/SVM guidelines for the diagnosis and management of patients with thoracic aortic disease. A Report of the American College of Cardiology Foundation/American Heart Association task force on practice guidelines, American Association for Thoracic Surgery, American College of Radiology, American Stroke Association, Society of Cardiovascular Anesthesiologists, Society for Cardiovascular Angiography and Interventions, Society of Interventional Radiology, Society of Thoracic Surgeons, and Society for Vascular Medicine. J Am Coll Cardiol. 2010;55: e27-129.

40. Chen Y, Ma WG, Zheng J, Liu YM, Zhu JM, Sun LZ. Total arch replacement and frozen elephant trunk for type A aortic dissection after Bentall procedure in Marfan syndrome. J Thorac Dis. 2018;10:2377-87.

Key Words: aortic dissection, computed tomography, frozen elephant trunk, longitudinal analysis, Marfan syndrome, reoperation, survival

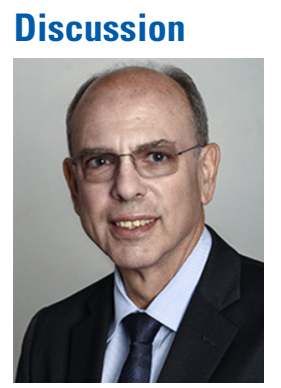

Dr Steven Lansman (Valhalla, NY). Dr Sun and colleagues at Anzhen Hospital in Beijing have one of the largest experiences in the world of total arches and fixed elephant trunk procedures for acute type A dissection. Although this study includes just 172 cases, it is a small subset of that huge experience, but these are valuable data because they represent one of the largest experiences of endografting in patients with MFS. I have 1 comment and 3 questions.

The comment is, in the series we published at Mount Sinai, only $8 \%$ of patients had multiple tears, whereas in this study more than $50 \%$ of this cohort of patients with MFS had multiple tears and $96 \%$ had dissected arch vessels. So that leads to my first question. There is a concern about tissue integrity in connective tissue disorders, and the American College of Cardiology/American Heart Association guidelines and consensus statements advise against endovascular approaches in acute and chronic aortic problems in MFS. Limited evidence has shown reasonable early results but significant late problems, one of which is stentinduced new entry. Have you observed this problem in your series, and along the same lines, have you had any late problems?

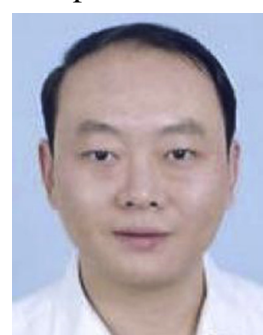

Dr Wei-Guo Ma (Beijing, China). Thank you, Dr Lansman, for your comments and questions. About your comments regarding the tear in the arch, our series is different from the Mount Sinai series, because all patients in the Mount Sinai report were with acute type A dissection, and if I am correct, only a small percentage of patients had MFS (8.8\%, 15 of
179). In our series, all patients had MFS, and $45 \%$ of the patients had chronic type A dissection.

It is our speculation that the dissected aorta undergoes substantial changes during the temporal course and it may take longer time for the distal aorta to develop multiple tears in the transition from an acute to a chronic dissection over time. This means that multiple tears may be more common in chronic dissections than in the acute phase. The percentage of chronic dissection in this series is $45 \%$, much higher than the $8 \%$ in the Mount Sinai series. So we think that is why we observed such a high percentage of multiple tears in this series.

In our series, we had 4 patients who developed a distal entry tear after surgery, in whom CTA at discharge showed that the distal end of FET entered the false lumen. The distal aorta remained stable in one patient. The other 3 underwent thoracoabdominal aortic replacement due to distal aortic dilation. All 4 patients survived to the latest follow-up. In the present series of Marfan patients with type A dissection, we did not observe any cases of other late problems, such as erosion to the esophagus or pseudoaneurysm formation. However, we have observed these problems (pseudoaneurysm and fistula) in patients with MFS undergoing thoracoabdominal aortic repair.

Dr Lansman. That is reasonable, but it is a good segue to my next question that relates to the late reoperation rate because connective tissue disorder has been shown to be a risk factor for this complication in a number of multivariable analyses. Your analysis combines 94 acute and 78 chronic dissections, but the chronic cases may have stabilized somewhat. Did you look at the late reoperation rate in just the acute cases? It is in the range of $10 \%$ to $15 \%$ in a series that I just looked at. Is it similar? Have you looked at that?

Dr Ma. The reoperation rate was higher in this series of patients with MFS than in our experience with other patients without MFS. At 10 years, the reoperative rate was approximately $20 \%$ to $22 \%$ for acute type A dissections in patients with Marfan syndrome.

Dr Lansman. That's for acute.

Dr Ma. For non-Marfan patients, the rate of reoperation was less than $10 \%$ at 10 years in our experience.

Dr Lansman. Okay. What percent does that comprise of your overall type A experience, and do you know whether the prevalence of Marfan disease is similar in China as in the United States and Europe?

Dr Ma. I think the prevalence of Marfan disease is a bit different between China and the United States and Europe. In a series of 1063 patients we reported last year at the Annual Meeting of the American Association for Thoracic Surgery, there were 587 acute type A dissections and 476 chronic type A dissections. Among them, there were 40 Marfan patients with acute type A dissection and 66 Marfan patients with chronic type A dissection. The percentage of 
MFS was $7 \%$ in acute type A dissection and $14 \%$ in the chronic dissection in our series. The prevalence of Marfan syndrome in our series was higher than in the International Registry of Acute Aortic Dissection (IRAD). The latest IRAD data show that $5 \%$ of patients with type A dissection had Marfan syndrome.

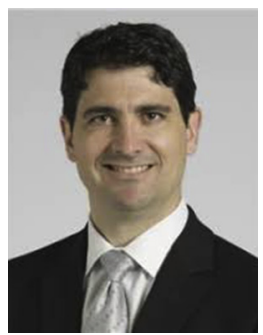

Dr Eric Roselli (Cleveland, Ohio). You showed that the maximum diameter and patent FL were late risks for growth of the aorta, similar to what we have seen with some of the prior IRAD data and what we have seen in much type B dissection data. I also thought it was interesting that you had an $80 \%$ freedom from reoperation, which seemed high. In our series, we looked at patients with connective tissue disorder who had more extensive operations beyond the root with a $60 \%$ freedom at 10 years, but I think we were getting to them later, which suggests to me that perhaps you were being more protective in these operations by getting their aorta remodeled sooner with the FET.
So my question is, because we see that these patients do respond to this therapy similar to patients without connective tissue disorder, they change faster, should we be more aggressive with applying TEVAR in some of these patients when we are seeing that growth at the diaphragm or maybe even doing what the Australians are doing where they are covering the whole thing with a bare-metal stent?

Dr Ma. Yes, I think we should be more aggressive in the use of open or endovascular stent grafting for patients with MFS, because the aorta of these patients will dilate definitely, sooner or later. If we intervene earlier, the intervention will at least delay the time to reoperation. If we add a bare-metal stent at the distal end of the FET, it may help the remodeling across longer aortic segments, and with a stent graft in place it will help reduce the reintervention rate. I think this is a good method to promote remodeling of the distal aorta. I have seen some reports on the use of the PETICOAT or the STABILISE technique for Marfan patients with aortic dissection, which involves using a baremetal stent in the distal aorta. Thank you.

Dr Roselli. It certainly seems reasonable to study. 